\title{
Dentistry at the Crossroad-Profession and Entrepreneurship
}

\author{
Mahyunah Masud $^{1 *}$, Anisah Lokman', Mohamed Ibrahim Abu Hassan ${ }^{1}$ \\ ${ }^{1}$ Faculty of Dentistry, Universiti Teknologi MARA, Shah Alam, Malaysia
}

*Corresponding Author: Mahyunah Masud, Faculty of Dentistry, Universiti Teknologi MARA, Shah Alam, Malaysia; Email: mahyunah@uitm.edu.my

Received Date: 24-05-2020; Accepted Date: 25-05-2020; Published Date: 31-05-2020

Copyright $^{\circledR} 2020$ by Masud M, et al. All rights reserved. This is an open access article distributed under the terms of the Creative Commons Attribution License, which permits unrestricted use, distribution, and reproduction in any medium, provided the original author and source are credited.

\section{Editorial}

Profession is a paid occupation involving prolonged and specialized preparation and training at the level of higher education. Dentist is a profession that focused on serving the oral health needs of patients and society, with the financial gain derived from the service they provided. Entrepreneurship in dentistry is undertaking both innovations and business acumen to transform them into economic goods. Today, increasing number of dentists practice in the field of health care, competing for patients, treat patients with the intention of earning a significant profit for their services. Being your own boss, setting your own hours, making a decent living and helping people in need are the major allure for entrepreneurship among dental professionals [1]. Since the future of health care after this pandemic episode of COVID-19 is hard to gauge, entrepeneurship in health related field especially in dentistry needs new direction. Serious new patient management approach to accommodate standing operative procedures would be the future of the profession and entrepreneurship.

Given the costs associated with educating dental students and preparing them for the real world, the Faculty of Dentistry, University Technology Mara, Malaysia requires students to take entrepreneurial subject, Technopreneurship (ENT 600) in their final year of studies that focuses on how to set-up a business at the same time linking the knowledge to General Dental Practice (GDP) patient management in Year 5. We did a study to assess the entrepreneurial potential of these students in the midst of their busy schedule of laboratory work, clinical responsibilities, module requirement and patient management. The study aimed to identify student's entrepreneurship background, activities and interest to participate in the programmes organised by the university. A self-administer questionnaires were distributed to 172 students encompassing Year 1 to Year 5 consisting of 32 males and 140 females with the age range of

Masud M | Volume 1; Issue 1 (2020) | JDHOR-1(1)-005 | Editorial

Citation: Masud M, et al. Dentistry at the Crossroad-Profession and Entrepreneurship. J Dental Health

Oral Res. 2020;1(1):1-3.

DOI: http://dx.doi.org/10.46889/JDHOR.2020.1105 
19-25 years old. Twelve questions were included in the questionnaires and data was analysed using statistical package SPSS.

The result showed that $64.4 \%$ of students were or has been involved in business and $62.6 \%$ were interested in opening their own business after graduating with $48 \%$ of them intended to register and own a company. $45.6 \%$ showed interest in the entrepreneurship programmes organised by the faculty and this could have been contributed by the parent's background having some influence on the children entrepreneurship interest, as $23.3 \%$ were self-employed, $15.7 \%$ worked in private and $39.3 \%$ as government employees. When asked on business experience, $7.1 \%$ have registered a company and $46 \%$ intended to register on graduation when $61 \%$ had some business or cooperative experience in school and colleges.

This study showed that dental students have entrepreneurship exposures with more than half were involved in the activities and interested in pursuing entrepreneurship after graduation. With the reduction of compulsory service in Malaysia from three to one year or may be later its abolishment, our students are well equipped for the practice of business in health care providers and venture into entrepreneurship. Three keys to transition from dentist to dental entrepreneur are that, one need to build a solid foundation, hire good people to manage the growing business and to create an environment of learning that is fun and rewarding, at the end, ensure the lessons learned are put into actions. There is a need to consider the business side of dental practice in particular, the importance of quality, creativity and innovation, alongside the importance of meeting the need of patients. An entrepreneurial approach will be required in order to sustain dental practice in an increasingly competitive environment [2].

However, all the dentists of the world have performed nobly in the preventive area through promotion of water fluoridation, and with dental caries decreasing, periodontal conditions, prosthodontics, aesthetic requirements and adult dental care should largely replace restorative care for children. The nation's total dental bill thus may not decrease very much, but the improved distribution of dental care should result in far better dental health for the public and the birth of dental entrepreneurs [3]. They are driven not by security but by a vision and a passion for creating a significant dental enterprise that reflects values, vision and purpose. That distinguished a dental entrepreneur from the average dentist [4].

How would all these be after COVID-19? The novel COVID-19 has resulted in serious financial implications being faced by dental practices, hospitals and healthcare workers. Dental practice currently is restricted to provision of emergency dental care whereas many hospitals have also cancelled elective procedures to save finances for COVID-19 treatment which is expensive and unpredictable. In addition, healthcare workers are also facing financial challenges in this difficult time. Competent authorities should assist to ensure efficient provision of healthcare in all sectors in these testing times and beyond. Stay home, stay safe. 


\section{References}

1. Singh A, Purohit B. Dental Entrepreneurship-A transitional phase to generation next. Adv Life Sci Technol. 2011;2(25):26-30.

2. Willcocks S. The entrepreneurial role in primary care dentistry. Br Dent J. 2012;212(5):213-7.

3. Cooper M. 11 qualities of the TRUE dentist entrepreneur. Dent Prac Management. 2017.

4. Farooq I, Ali S. COVID-19 outbreak and its monetary implications for dental practices, hospitals and healthcare workers. Postgrad Medical J. 2020. 